\title{
The Consultation System Design for the Yellow River Engineering Danger
}

\author{
Huang Kui \\ Yellow River Institute of Hydraulic Research, Zhengzhou;1741479907@qq.com
}

Keywords: consultation system; technical support; overall structure; key technology

\begin{abstract}
The Yellow River engineering danger consultation system can provides the technical support for the Yellow River scheduling management and how to make decisions and directions. The article studied overall structure of the system and key technology including Data management technology, GIS technology development, B/S structure technology. It can help decision makers to make scientific decision, and to improve the efficiency of management.
\end{abstract}

Along with the development of computer technology, information technology has been widely used in water conservancy industry ${ }^{[1]}$. The Yellow River is the integrated use of digital information technology, to construct a digital integrated platform for Yellow River basin and its related areas of nature, economy, and the society and so on ${ }^{[2]}$. Using remote sensing, GPS and other modern methods to realize information transmission network, information management, the main business intelligence, and digital electronic of government affairs ${ }^{[3]}$. The consultation system design for The Yellow River engineering danger is the main part of "digital Yellow River", this system can provide visualize design flood control information, to help decision makers to make scientific decision, and to improve the efficiency of management.

\section{Overall structure of the system}

System overall function. The Yellow River engineering danger consultation system can provides the technical support for the Yellow River scheduling management and how to make decisions and directions. The main design function including the following respects. (1) Through the vector map, establish the Yellow River electronic map and the downstream channel of electronic map (2) using the advanced database technology to design and development the project risks database and information management system.(3) using the electronic maps to inquire the basic situation of the Yellow River.(4) Through the electronic maps and inquiring the basic hydrology information of the Yellow River. One can realize the following goals like: animation cloud simulations, water basic inquire rainfall regime information query and promptly period of rainfall isoline, contour surface analysis. (5) Flood control engineering information query include dangerous section of a project, river training project engineering, rolling river protection engineering, levee project, sluice gate engineering, basic information such as flood storage project.(6) Basic information inquires of Flood control deployment. Inquires include the basic information like flood control organization team and flood control warehouse materials, etc(7) Flood control plan information query.(8) Flood control file material management and inquiry(9) Real-time situation of reporting and inquiring. Real-time danger reporting, alarm, processing, and inquires displayed. (10) Flood control road inquires statistics and the optimal path analysis(11) Develop a combination of geographic information analysis, and statistical process(12) Artificial regime plot and remote sensing regime analysis(13) Flood control project object position information description analysis(14) Combined with the database upgrade for spatial data and database management(15) Related information query. Including: hydrological forecasting results inquires and flood control dispatching results inquires,ect.(16) Map rent pattern development(17) Different scale of atlas automatic navigation(18) The Yellow River downstream channel of typical model based on the orientation of river DEM inquiry module.(19) Explore relevant model based on GIS transplanted to the platform in consultation system. 
System structure. Practicing situation of project and danger situation of a project consultation system uses the three-layer structure (Show in figure 1). The upper layer is application development, mainly for flood control consultation of the business process. Rapid build the basic applications, in order to maintain a high level of flexibility and expansibility. The main interface takes GIS visual interface. The bottom is using for data collection and storage, focusing on building the information reported structure with integrity and stability and the construction process of the scientific data storage structure; The database structure is divided into three parts: geographic information database, the practicing and danger situation of a project, and the original real-time water rainfall regime library. The middle layer is database platform and geographic information platform technology itself, providing tools interface for the upper application development, using the mature products to provide the middleware development tools interface, fast transplantation and build all kinds of flood control and application system. The middle layer geographic information management uses mature WEBGIS G2MEngine middleware.

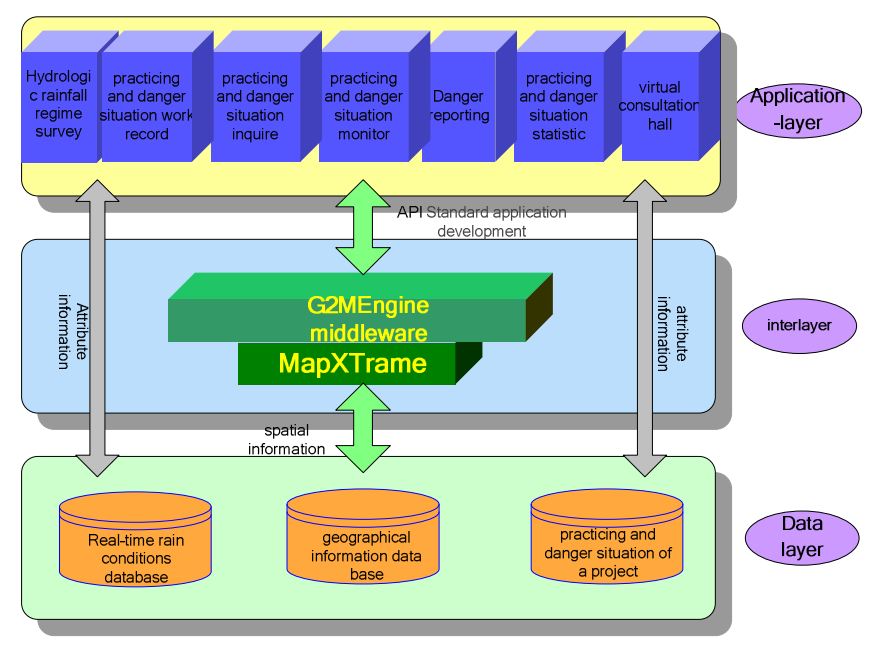

Figure 1 System the basic framework

Overall Structure of one system. System is based on work, the sentiment database and geographic information database, and connect the real-time water rainfall regime database to meet the real-time water rainfall regime query, With the support of the Yellow River map, the Yellow River downstream channel map and other electronic map, combined the information management system and geographic information system, using $\mathrm{C} / \mathrm{S}$ and $\mathrm{B} / \mathrm{S}$ two complementary operating mode, and to realize hydrology information query, flood control engineering foundation information query, basic flood control and deployment information query, real-time project operation and dangerous omen situation of a project information report, the inquiry statistics, real time information processing, the alarm, displayed, the official reply, and functions like system management maintenance etc. (1) hydrology information query. The Yellow River basin as the background are used to show water system, and water system boundary, hub project, hydrology water level and rainfall site, etc. If Given the time period it has the ability for rainfall regime information query and analysis promptly period of rainfall isoline, algorith. (2) The flood control engineering basic information query. The query can include danger, dyke projects, sluice engineering, as well as based information such as storage project; (3) flood control basic information inquires deployment. The query can include flood control organization, flood control team and basic message like warehouse materials. (4) Real-time practicing and dangerous situation information report, the statistics inquiry. Real-time practice report, practice inquiry, real-time danger report, dangerous omen inquire statistics etc. (5) real-time danger alarm. Including real-time danger alarm and real-time danger query; (6) real-time danger alarm: can alarm on time when there is dangerous exist. After the report, the superior department computer can be on duty to make a quick response with sound alarm and displayed. And can browse their description. The real-time danger query: displays real-time danger, one can visit the danger description; (7) the official reply of the danger. When monitor there is danger exist, 
superior departments can instruct and review the report from the lower department,. The replay include rescue schemes and plans, it can also use the words \& pictures to describe the scheme. It includes replying to the danger, replying inquiry, modifying and showing to the replay.



Figure 2. The lower Yellow River feeling to the danger of the whole system work in consultation with the structure

\section{Key technology}

Data management technology. Data management use Sybase database. Use Windows 2000 Server as a network operating system platform, WEB Server using Microsoft Internet Information Service 4.0/5.0 (IIS4.0 / IIS5.0).Using OLE DB to provide access to database, it supports ISAPI, CGI programs, ASP application, etc. Provide COM/COM + interface, the developers could through the $\mathrm{COM} / \mathrm{COM}+$ interface to enhanced with custom WEB server functions, it has the very good flexibility; Provides a powerful database support function, it can also through ADO/ODBC/IDC to access the database, and easily develop the database application system based on Internet; Combine with Windows 2000 Server operating system closely, can save a lot of system resources, and to use the application system efficient operation; Provides efficient multithreading service mechanism and the safety management mechanism, which enables the system operate with more security and stability.

Programming software use PowerBuilder. It is a highly efficient and fast integrated development environment and provide the visualization, object-oriented, based on client $\sim$ server development environment, so it gets a strong ability of data extraction. Using the abundant functions of DataWindosObject and function can design and development the data access display mode, data validation, Shared data, and other functions.

Management system is a strong interactive database application system, using a variety of WEB technology to realize the dynamic interaction system, which is combined the ASP, ActiveX, Java method, to realize the system functions like processing and interaction. For database access uses ASP technology; using java for image processing, network transmission, check for the wrong; For some applications model using ActiveX technology. Through the organic combination of these technologies, it can form a powerful, reasonable design, convenient use, strong interaction application system.

In the design of the storage structure you must do your best to eliminate redundant data, using optimal storage and inquires system of Sybase to reduce resources consumption like: internal memory, external memory and CPU.

GIS technology development. MapInfo has space data acquisition, spatial data management, application programming control and other advanced technology. Through using and development of these technologies, to provide a consultation interface which has a rich visual expression information and completeness of the content, this is beneficial to the information of the deep mining and analysis. 
Desktop map software MapInfo Professional. MapInfo Professional has complex but detailed spatial data analysis and data management performance ability, can help users from geography Angle to better understand the information. First of all, cartographic scan and vectorizing the Yellow River diagram and the Yellow River downstream channel map, hierarchical storage according to the different categories of map elements, then geographical coding the map to establish an association between data objects and the map.

Programmable control MapInfo. MapX is efficient and powerful ActiveX components, it can be easily integrated to use standard visual programming tools developed applications. MapX provides an object model, a large number of methods and events, efficient property page and the default value, as well as other guide, to help simplify the application development. In programming language Visual Basic 6.0, using MapX control to add map functions into applications, including the map view, operation and thematic mapping function and including zoom, wandering, inquires to measure and control layer, distance, user control, through remote data access based on component technology and the object links and ADO embedded OLE technology to realize the attribute data and the spatial data connection, providing highly Visual method to display and analysis data which is based on the locations.

Internet/Intranet's map application server MapXtreme and map system G2MEngine middleware. MapXtreme is used for Internet/Intranet map server and can be used in the widespread maps produce and analysis based on the positions. MapXtreme uses as the bottom platform of the map, with map system G2Mengine middleware, to provide for the application development a highly visual, intuitive component, easily to add the map function to any Web applications.

B/S structure technology. MapXtreme and Middleware products of G2Mengine support running map application on a centralized server, and reduce hardware and management costs and the workload of development, installation and maintenance of client software, while also support multiple WEBGIS server working clusteredly, collaboratively and mutually backing up, thus improving performance, reliability and security greatly.

We develop online virtual consultation hall -- based on MapXtreme technology and middleware technology -- on Yellow River Conservancy Intranet, allowing all the end-user to only install browser software on their own specific PC (such as Microsoft Internet Explorer and Netscape) in order to access spatial data stored on the server, and, basing on electronic maps, to analyze related information concerning water and rainfall conditions, construction conditions and danger conditions.

\section{Operating system environment}

Network environment. Yellow River engineering condition, danger condition consultation with the system computer network protocol is TCP / IP.

Hardware environment. Database server: high-end PC server, dual CPU, 512MB ram, hard disk at least 60G. Map Server: high-end PC server, dual CPU, 1G of memory, hard disk at least 60G. Client: PIII500 or higher, 128MB ram, hard disk at least 10G. Consultation-dedicated machine: PIII500 or higher, $256 \mathrm{MB}$ ram, hard disk at least $10 \mathrm{G}$.

Software environment. Network server: WINDOWS 2000 the SERVER. Map application server software: MapXtreme2.0, Map engine Middleware: G2Mengine5.0. Database software: SYBASE11.05 the. Web servers: IIS4.0.

\section{Conclusions}

The danger consultation system of the Yellow River Project provides convenient conditions for the sharing of information, users access and use the various functions of GIS application system via the WWW browser, thus keeping flood control duty officers promptly informed of dangerous situation, and making the content of flood control consultation and the level of demonstrated information further enriched, facilitating flood control headquarters ${ }^{[4]}$, providing flood control consultation with the multi-dimensional information service and technical support. 


\section{References}

[1] WU Hui,YAO Bao-shun.GIS application in the Yellow River flood control practice[J].19-26.

[2] LIU Hao,YIN Si-qing. The application of data mining technology in "Digitalized Yellow River"project construction[J].Computer Knowledge and Technology,2009,5(1):23-24.

[3] ZHOU Zhen-hong, ZHANG Jun-jing,CHEN Shi-feng. Digital Huanghe engineering and key supporting technique[J]. Journal of Zhengzhou unversity (engineering science). 2003, 24(2): 59-66.

[4] DING Bin.Consulting system on flood control engineering information and flood caused engineering information of the downstream of Yellow River based on WbeGIS. 2008,29(5): 15-17.) 